\title{
The Effects of Filler Contents and Particle Sizes on the Mechanical and End-Use Properties of Snail Shell Powder Filled Polypropylene
}

\author{
Genevive C. Onuegbu, Isaac Ogbennaya Igwe
}

Department of Polymer and Textile Engineering, Federal University of Technology, Owerri, Nigeria.

Email: izikigwe@yahoo.com

Received February 21 ${ }^{\text {th }}, 2011$; revised March $4^{\text {th }}, 2011$; accepted March $16^{\text {th }}, 2011$.

\begin{abstract}
Polypropylene composites of snail shell powder were prepared at filler contents, 0 to $40 \mathrm{wt} \%$. The particle sizes of the snail shell powder investigated were $0.150,0.30$, and $0.42 \mu \mathrm{m}$. Talc, of particle size, $0.150 \mu \mathrm{m}$ was used as the reference filler. The polypropylene composites were prepared in an injection moulding machine and the resulting composites were extruded as sheets. Some mechanical and end-use properties of the prepared composites were determined. Results showed that the snail shell powder improved the tensile modulus, flexural strength, and impact strength of polypropylene and these properties increased with increases in the filler content and decreases in the filler particle size. The elongation at break of the composites was however observed to decrease with increases in the filler content, and particle size. The elongation at break of talc filled polypropylene was zero, an indication of the brittle nature of polypropylene composites of talc. The hardness, water sorption (24-hr) and specific gravity of the composites were found to increase with increases in the filler content, and decreases in the filler particle size. The level of water absorbed by snail shell powder composites of polypropylene is considerably higher than that of talc filled polypropylene. The flame retardant properties of the prepared composites were however found to decrease with increases in the filler content, and particle size. Generally, snail shell powder was found to show greater property improvement over talc in the prepared composites.
\end{abstract}

Keywords: Filler, Particle Size, Polypropylene, Snail Shell powder, Composite

\section{Introduction}

The past decades have witnessed increasing interest in the use of fillers in the polymer industry. Fillers greatly enhance the dimensional stability, impact resistance, tensile and compressive strength, abrasion resistance and thermal stability when incorporated into polymers. Fillers which merely increase the bulk volume, and hence, reduce price, are known as extender fillers while those which improve the mechanical properties particularly tensile strength are termed as reinforcing fillers [1-4] .

Polypropylene is one of the most important polyolefin's that have wide rage of applications. Presently, there has been an increase in the use of filled polypropylene in electrical and automotive engineering. This is mainly due to the excellent stiffness property which polypropylene exhibits and which enables it to substitute conventional materials in demanding engineering applications [5]. Typical fillers for polypropylene are glass fibres, glass sphere, talc, asbestos, calcium carbonate, silica and mica. The use of mineral fillers and fibres in making polymer composites has certain drawbacks. For example, a lot of energy is required in the processing of glass fibres since their processing temperatures can exceed $1200^{\circ} \mathrm{C}$. Glass fibres also tend to abrade processing equipments, and increase the density of the plastic system [6].There has been a conbined search for filler materials in compounding polypropylene and which is likely to grow with the introduction of improved compounding technology, and new coupling and compatibilizing agents that permit the use of high filler/reinforcement content [7]. As suggested by Kartz and Milewski [7], fillings up to 75 parts per hundred(pph) could be common in future.

Different filler materials have been studied for making polypropylene composites. These materials included wood, kenaf and sage fibres [8], saw dust [9], flax [10], hemp strand [11], green coconut fibre [12], and organo-montmorillonite [13]. Thus, Fan et al. [14] who 
studied polypropylene-montmorillonite nanocomposites reported a decrease in modulus and tensile strength of the composites with increasing clay content. Similarly, Chen et al. [15] who investigated the properties of polypropylene filled with magnesium hydroxide reported that the addition of magnesium hydroxide improved the flame retardant property of polypropylene/magnesium hydroxide composites, but seriously deteriorated the mechanical properties. Recently, the use of snail shell powder as a filler in making polypropylene composite was reported [16]. Snail shell powder contents of 0 to $5 \mathrm{wt} \%$ were investigated at a powder particle size of $0.30 \mu \mathrm{m}$. The properties of the polypropylene composites determined were the specific gravity, water sorption (24-hr), flammability, and hardness tests.

In the present report on further utilization of snail shell powder in filling polypropylene ,the central objectives are to (i) investigate fully the properties of polypropylene composites of snail shell since the work reported above [16] was considered exploratory and limited in scope, (ii) determine the effects of snail shell powder particle size on the properties of polypropylene composites. Snail shell powder contents of 0 to $40 \mathrm{wt} \%$ were used in this study.

Besides the work reported above [16] ,the use of snail shell powder in filling polypropylene or any other thermoplastic had not been reported in the scientific literature to our knowledge. Snail shell is a domestic waste. The waste presently does not have any known domestic application in our locality, and could be found littering dust bins in our big cities and farm yards in villages.

\section{Materials and Method}

\subsection{Materials}

The polypropylene used in this study was obtained from Eleme Petrochemical Company Limited, Rivers State, Nigeria. It has a melt flow index of $2.5-3.5 \mathrm{~g} / \mathrm{min}$, and density, $0.926 \mathrm{~g} / \mathrm{cm}^{3}$. The snail shell from which snail shell powder was produced was collected locally within Owerri metropolis, Imo state, Nigeria .The shell was properly treated to remove impurities before it was crushed and sieved to three particle sizes namely, 0.150, 0.30 , and $0.42 \mu \mathrm{m}$. Talc which was used as a reference filler was purchased from a Chemical Store at Owerri, Imo State, Nigeria.

\subsection{Preparation of Polypropylene Composites}

The polypropylene composites of snail shell powder were prepared by thoroughly mixing $40 \mathrm{~g}$ of polypropylene with appropriate filler quantities $(0,5,10,20,30$ and $40 \mathrm{wt} \%)$. The polypropylene was melted and ho- mogenized with the filler in an injection moulding machine. The resulted composites were extruded as sheets. The polypropylene composites of talc were prepared only at filler particle size, $0.150 \mu \mathrm{m}$.

\subsection{Testing}

The tensile strength (ASTM D 638), tensile modulus (ASTM 1822), flexural strength (ASTM D 790-97), impact strength (ASM D256), rock well hardness, (ASTM D 785), specific gravity (ASM D 792), and water sorption (24-hr) (ISO 180) properties of the prepared polypropylene composites were determined using standard methods. A modification of ASTM D 4804 was used to determine the flammability rate of the composites. Since polypropylene filled or unfilled is a thermoplast, flame spread is regarded as the rate of melt-burn, i.e., the rate at which the original length of the specimen decreases as flame/heat spreads along the specimen. The flammability rate (FR) is expressed as,

$\mathrm{FR}(\mathrm{mm} / \mathrm{s})=\mathrm{D}_{\mathrm{p}} / \mathrm{P}_{\mathrm{t}}-\mathrm{I}_{\mathrm{t}}[1]$

where $D_{p}=$ Propagation distance measured in millimetre.

$\mathrm{P}_{\mathrm{t}}=$ Flame propagation time measured in seconds.

$\mathrm{I}_{\mathrm{t}}=$ Ignition time measured in seconds.

\section{Results and Discussion}

\subsection{Mechanical Properties}

The mechanical properties of polypropylene composites prepared in this study have been determined and the results are illustrated graphically as shown in Figures 1-5. Talc was used as the reference filler in this study since it is one of the standard fillers in use in the plastic industry [13].

\subsubsection{Tensile Strength}

Figure 1 shows the effect of filler contents, and particle sizes on the tensile strengths of unfilled, and filled polypropylene. The tensile strength of polypropylene composites was observed to increase with increases in with increases in snail shell powder content and particle size. From Figure 1, it is clear that the smaller the particle size of snail shell power, the higher the tensile strength of the polypropylene composite at any snail shell powder content and particle size considered .The better dispersion and filler-matrix interaction may be the two main reasons or factors responsible for the observed trend. Similar observations have been reported by Bigg, [17], and Fuad et al. [18] for other filled systems. However, Fan et al. [14] reported decreases in tensile strength of polypropylene-montmorillonite composites with increases in clay content. 


\subsubsection{Tensile Modulus}

Figure 2 illustrates the effects of snail shell powder content, and particle size on the tensile modulus of prepared polypropylene composites. Like was observed on the effect of filler content and particle size on the tensile strength of filled polypropylene, the modulus of the composites increased with increases in filler content and filler particle size. This observation highlights the fact that the incorporation of fillers into polymer matrix improves the stiffness of the composites [19]. The snail

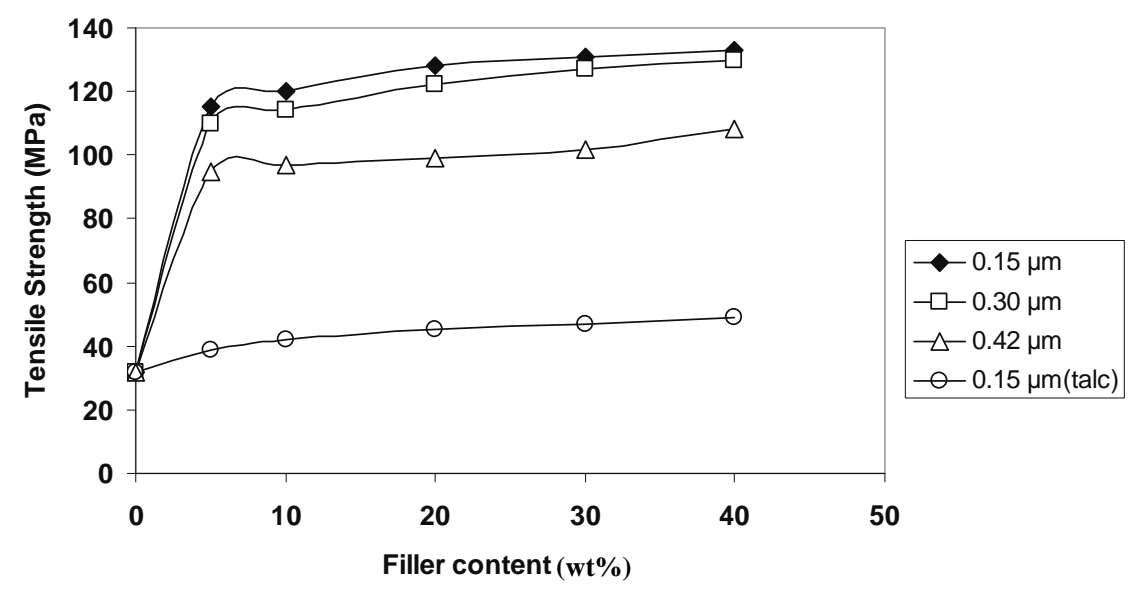

Figure 1. Tensile strength versus filler content for polypropylene composites at different filler particle size.

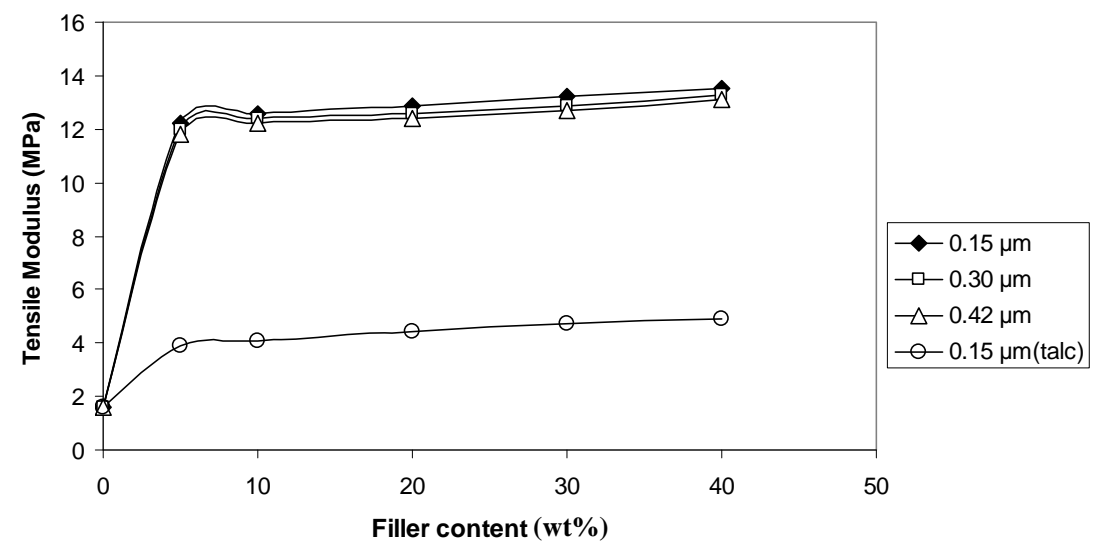

Figure 2. Tensile modulus versus filler content for polypropylene composites at different filler particle size.

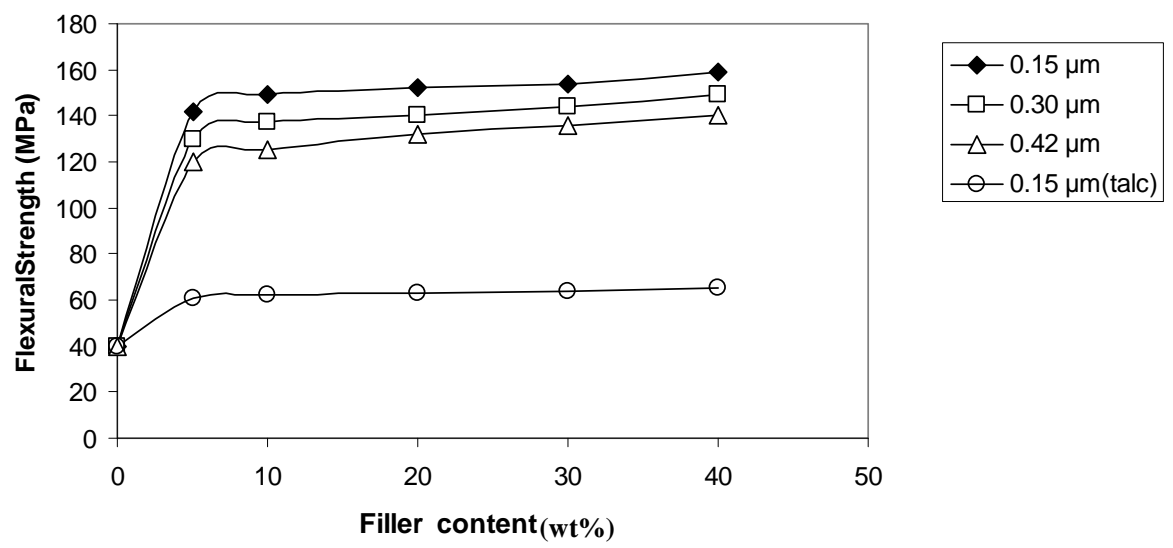

Figure 3. Flexural strength versus filler content for polypropylene composites at different filler particle size. 


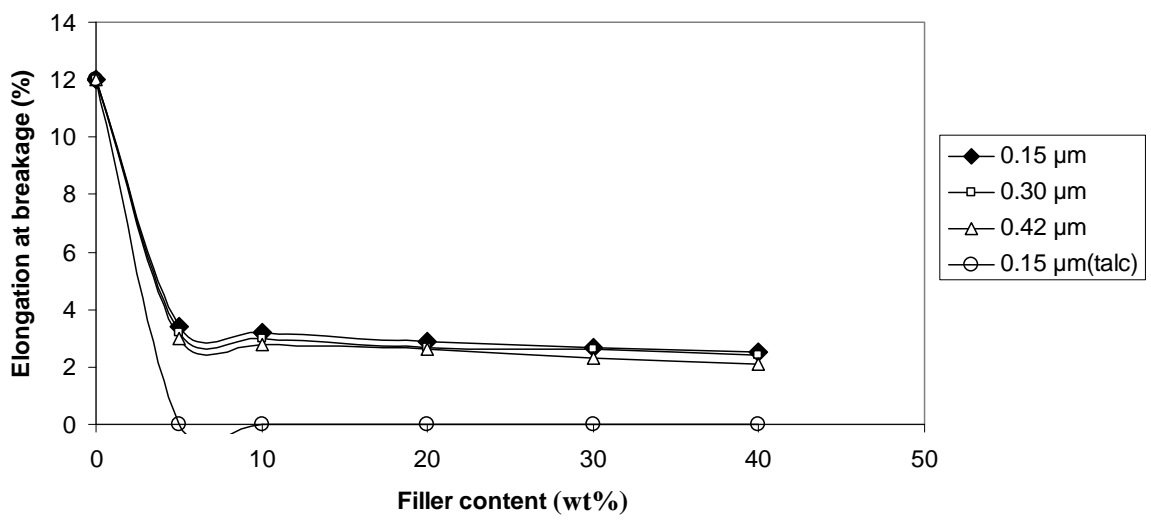

Figure 4. Elongation at breakage versus filler content for polypropylene composites at different filler particle size.

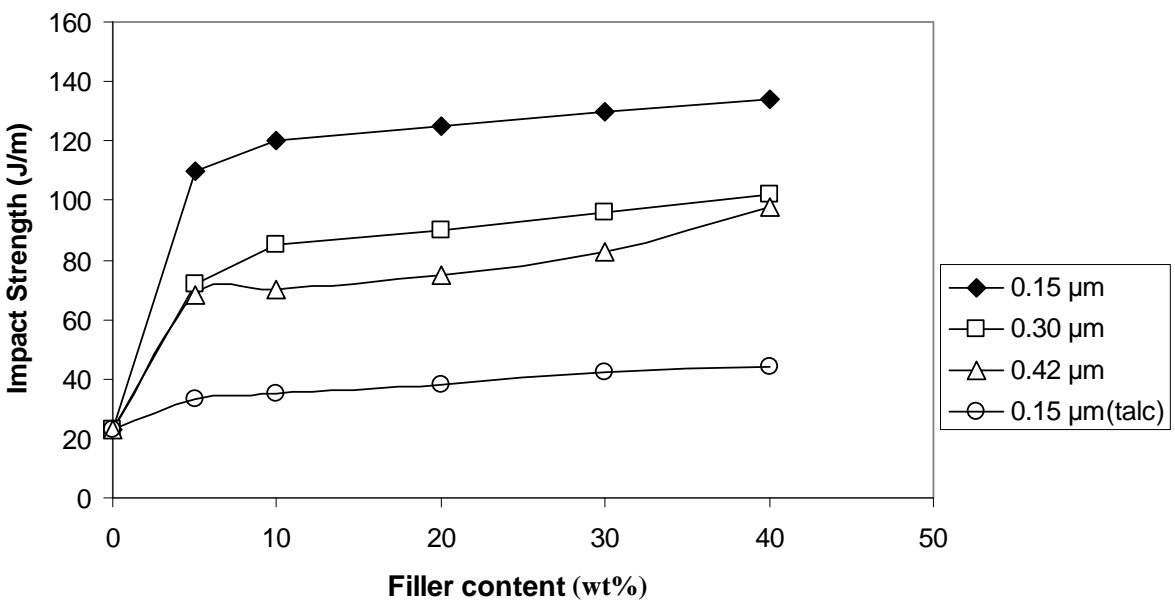

Figure 5. Impact strength versus filler content for polypropylene composites at different filler particle size.

shell powder exhibited higher tensile modulus on the composites than talc, the reference filler.

\subsubsection{Flexural Strength}

From Figure 3, the flexural strength of polypropylene composites is observed to increase with increases in filler content, and decreases in filler particle size.

Embu et al. [20] who studied the effect of mica content on the mechanical properties of polypropylene composites reported increases in the flexural strength of the composites with increases in mica content. The present study shows that snail shell powder is superior to talc in improving the flexural strength of polypropylene.

\subsubsection{Elongation at Break}

Figure 4 shows that the elongation at break for snail shell powder-polypropylene composites decreases with increases in filler content at any given filler particle size considered.

Fillers can be considered as structural elements embedded in the polymer matrix, and at the concentrations of the filler used ( 0 - $40 \mathrm{wt} \%$ ), the contents might not be high enough to significantly restrain the polypropylene molecules. Consequently, highly localized strains might have occurred at the concentrations investigated, causing dewetting between polypropylene and the filler, and thus, leaving essentially a matrix that is not ductile. Such a reduction in elongation at break of a composite with increases in filler content, irrespective of filler particle size has been reported by Ismail et al. [21]. Figure 4 shows that the elongation at break of the polypropylene composites decreases with increases in the filler particle size. It is very interesting to note that in the present investigation, talc filled polypropylene did not exhibit any elongation at break, an indication that talc filled polypropylene is brittle and would not be suitable for some of the applications of polypropylene composites.

\subsubsection{Impact Strength}

The impact strength of polypropylene composites of snail shell powder at a particular filler particle size was observed to increase with increases in snail shell powder content (Figure 5). 
The increase in impact strength of the prepared composites was very remarkable for snail shell powder composites of polypropylene than was for talc. This remarkable performance indicates that snail shell powder was more effective in distributing the applied stress over a large volume at the base of the notch, and which helped to prevent propagation of cracks by carrying large part of the load in the area under the crack. The increase in impact strength of a polymer composite with increase in filler content has been reported in the literature [17]. The impact strength of the prepared composites for particular filler and at a given filler content was observed to decrease with increase in filler particle size. Thus, increasing the particle size of snail shell powder at a given filler content probably increased the level of stress concentration in the composites with the resultant decrease in impact strength.

\subsubsection{Hardness}

At a given filler particle size, the hardness of polypropylene composites was observed to increase with increase in the amount of filler incorporated into polypropylene (Figure 6).

This result indicates enhancement of abrasion and impact strength of the composites. Generally, the hardness of the composites could be observed to decrease with increase in the particle size of the filler at a given filler content. Such a decrease in the hardness of polypropylene composites with increases in filler particle size was reported by Kokta et al. [22].

\subsubsection{Water Sorption (24-hr)}

The water sorption (24-hr) indices of polypropylene composites are shown in Figure 7. All the composites showed increases in water absorption with increase in filler content at all the filler particle sizes investigated.

Unlike all the other property parameters of the prepared composites discussed, the variation of water absorption with snail shell powder content and particle size is not much, an indication that water absorption by snail shell powder composites of polypropylene does not depend strongly on the filler content or particle size. All the prepared snail shell powder composites of polypropylene sorbed more water than that of talc, the reference filler. Generally, the level of water absorption observed for snail shell powder composites of polypropylene is considerably higher than those for other mineral filled systems. Although, water absorption could lead to a decrease in the end-use applications of these composites, there is reason to believe that by understanding the limitations and benefits of these composites, snail shell powder is not likely to be ignored by the plastic industry for use in formulating plastic products.

\subsubsection{Specific Gravity}

Figure 8 shows a general increase in the specific gravity of the composites with increases in filler content at any given filler particle size considered.

However, there was a general decrease in the specific gravity of the composites with increase in snail shell powder particle size at any given snail shell powder content considered. The increase in the specific gravity of snail shell powder composites of polypropylene with a reduction in filler particle size could be attributed to the greater uniform distribution of the small sized filler in the matrix. It is interesting to note that the specific gravity of glass, talc, and mica filled polypropylene are 1.23, 1.27, and 1.26 respectively [23], values which are less than those of snail shell powder filled polypropylene.

\subsubsection{Flame Propagation}

The rate of burning of the prepared composites of polypropylene at any given particle size of the snail shell powder considered was generally observed to decrease with increase in snail shell powder contents (Figure 9).

The above result indicates that the flame retardant property of polypropylene is enhanced by snail shell powder. Snail shell powder filled polypropylene was observed to reduce the rate of burning of polypropylene more than talc. The present flame retardant property of the snail shell powder investigated could be attributed to the following factors. Snail shell powder, like most other shells consists mostly of calcium carbonate [24]. On heating/application of flame, calcium carbonate decomposes according to the equation,

$$
\mathrm{CaCO}_{3} \stackrel{\Delta}{\rightarrow} \mathrm{CaO}+\mathrm{CO}_{2}
$$

with the evolution of carbon dioxide $\left(\mathrm{CO}_{2}\right)$ which does not support combustion. The more snail shell powder is incorporated into polypropylene, the more the quantity of calcium carbonate $\left(\mathrm{CaCO}_{3}\right)$ in the composites, and the less, the tendency of the composite to burn since $\mathrm{CO}_{2}$ is a good fire extinguisher. Further more, as a filler, the snail shell powder particles interact with the resin macromolecules. The adsorption of the macromolecules on the filler surfaces which would result in better chain alignment, also contributes significantly to the filler's flame retardant property .The net result of all these would be an intimate union between the filler particle and the binder. This is expected to raise the thermomechanical properties such as $\mathrm{T}_{\mathrm{m}}$ of the composite as against the unfilled polypropylene.

In this study, the effect of filler particle size on the flame retardant property of snail shell powder is not very apparent since all the particle sizes investigated exhibited similar flame retardant property. 


\section{Conclusions}

The mechanical and end-use properties of snail shell powder filled polypropylene have been determined in this study. Snail shell powder has shown greater property improvement over talc in the prepared composites. The specific gravity and hardness of snail shell powder filled polypropylene were observed to increase with increases in filler content, and decreases in filler particle size. The flame retardant property of polypropylene is greatly enhanced at high filler content, and filler particle size. With the exception of talc filled polypropylene, all the prepared composites investigated showed significant water absorption in a 24-hr water sorption test. The present study has highlighted the benefits of using snail shell powder as a filler for polypropylene. The results obtained suggest that the scope of application of polypropylene can be greatly broadened with the use of snail shell powder as a filler.

\section{Acknowledgements}

The authors express their gratitude to the staff of the Eleme Petrochemicals Ltd, Port Harcourt, Nigeria for their support in the preparation of polypropylene composites used in this study.

\section{REFERENCES}

[1] B. English, P. Chow and D. S. Bajwaz, "Processing Composites,” CRC Press, New York, 1997.

[2] K. Oksman and J. F. Selin, "Plastics and Composites from Polylactic Acid,” Kluwer Academic Press, Berlin, 2004.

[3] A. K. Bledzki and J. Gassan, “Composite Reinforced with Cellulose-based Fibres," Progress in Polymer Science, Vol. 24, No. 5, 1999, pp. 221-274. doi:10.1016/S0079-6700(98)00018-5

[4] D. Plackett, L. A. Logstrup, P. W. Batsberg and L. Nielsen, "Biodegradable Composites based on 1-Polylactide and Jute Fibres," Composites Science and Technology, Vol. 63, No. 9, 2003, pp. 1287-1296. doi:10.1016/S0266-3538(03)00100-3

[5] L. Sun, M. Xiao, P. Xiao, J. Song, W. Wang, Y. Zhang and K. Gong, "Electrical Properties of Metal Filled Polypropylene Composite," Society of Plastics Engineers, Annual Technical Conference, 1986, pp. 2230-2234.

[6] A. R. Sanadi, D. F. Caulfield, R. E. Jacobson and R. M. Rowell, "In: Kenaf properties, Processing and Products," Mississipi State University, Ag and Bio Engineering, Chapter 32, 1999, pp. 381-392.

[7] H. S. Katz and J. V. Milewski, "Handbook of Fillers for Plastic,” Van Nostrand Reinhold, New York, 1987.

[8] M. Gahleitner, B. Kretzschmar, D. Pospiech, E. Ingolic, E. Reichelt N. Reichelt and K. Bernreitner, "Morphology and Mechanical Properties of Polypropylene/Polyamide 6 Nanocomposites Prepared by a two-step Melt Compounding Process," Journal of Applied Polymer Science, Vol. 100, No. 1, 2006, pp. 283-291. doi:10.1002/app.23102

[9] S. K. Najafi, E. Hamidinia and M. Tajvidi, "Mechanical Properties of Composites from Sawdust and Recycled Plastics,” Journal of Applied Polymer Science, Vol. 100, 2006, pp. 3641-3645. doi:10.1002/app.23159

[10] J. Moran, V. Alvarex, R. Petrucci, J. Kenny and A. Vazquez, "Mechanical Properties of Polypropylene Composites Based on Natural Fibres subjected to Multiple Extrusion Cycles,” Journal of Applied Polymer Science, Vol. 103, No. 1, 2007, pp. 227-237. doi:10.1002/app.251739

[11] P. Mutje, M. E. Vallejos, J. Girones, F. Vilaseca, A. Lopez, J. P. Lopez and J. A. Mendez, "Effect of Maleated Polypropylene as Coupling Agent for Propylene Composites Reinforced with Hemp Strands,” Journal of Applied Polymer Science, Vol. 102, No. 1, 2006, pp. 833-840. doi:10.1002/app. 24315

[12] J. L. Leblanc, C. R. G. Furtado, M. C. A. M. Leite, L. L. Y. Visconte and M. H. Ishizaki, "Investigating Polypropylene-Green Coconut Fibre Composites in the Molten and Solid States through Various Techniques," Journal of Applied Polymer Science, Vol. 102, No. 2, 2006, pp. 1922-1936. doi:10.1002/app.24239

[13] W. W. Yi, Z. X. Fei, W. G. Guan and C. J. Feng, "Preparation and Properties of Polypropylene Filled with Organo-Montmorillonite Nanocomposites," Journal of Applied Polymer Science, Vol. 100, No. 4, 2006, pp. 28752880. doi:10.1002/app.23396

[14] Y. Fan, J. Lou and D. M. Shinozaki, "Microstructure Dependent Properties of Polypropylene-Clay Nanocomposites,” Applied Polymer science, Vol, 103, No. 1, 2007, pp. 204-210.

[15] X. Chen, J. Yu and S. Guo, "Structure and Properties of Polypropylene Composites Filled with Magnesium Hydrixide,” Applied Polymer science, Vol. 102, No. 5, 2006, pp. 4943-4951.

[16] I. O. Igwe, "Studies on the Properties of Polypropylene filled with Agricultural and Domestic Wastes," Journal of Research in Engineering, Vol. 4, No. 2, 2007, pp. 8-12.

[17] D. M. Bigg, "Mechanical Properties of Particulate filled Polymers,” Polymer Composites, Vol. 8, No. 2, 1987, pp. 115-122. doi:10.1002/pc.750080208

[18] M. Y. A. Fuad, Z. Ismail, Z. A. M. Ishak and A. K. M Omar, "Application of Rice Husk Ash as Fillers in Polypropylene: Effect of Titanate, Zirconate and Silane Coupling Agents,” European Polymer Journal, Vol. 31, No. 9, 1995, pp. 885-893. doi:10.1016/0014-3057(95)00041-0

[19] S. N. Das, T. K. Khastgir and D. K. Chakraborty, "Effect of Filler Blend Composition on the Electrical and Mechanical Properties of Conductive AVE Composite," Project Euclid, Vol. 8, 2002, pp. 457-634.

[20] Y. E. Embu, C. C. Briggs and R. J. Heath, “The Effect of 
Mica Reinforcement on the Mechanical Properties of Polypropylene," Nigerian Journal of Polymer Science, Vol. 1, No. 1, 2000, pp. 40-45.

[21] H. Ismail, H. D. Rozman, R. M. Jaffri and Z. A. Mohd Ishak, "Oil Palm Wood Flour Reinforced Epoxidized Natural Rubber Composites: The Effect of Filler Content and Size," European Polymer Journal, Vol. 33, No. 10-12, 1997, pp. 1627-1632. doi:10.1016/S0014-3057(97)00020-7

[22] B. V. Kokta, R. G. Raj and C. Daneault, "Use of Wood
Flour as Filler in Polypropylene: Studies on Mechanical Properties," Polymer Plastic Technology and Engineering, Vol. 28, 1989, p. 247.

[23] R. M. Rowell, A. Sanadi, R. Jacobson and D. Caulfield, "Properties of Kenalf/Polypropylene Composites," Mississipi State University, Ag and Bio Engineering, Chapter 32, 1999, pp. 381-392.

[24] A. S. M. Salenddin and K. M. Wilbur, "Chemical Composition of Snail Shell,” Journal of Zoology, Vol. 47, 1969, pp. 51-55. 